\title{
Exploring the Use of Visual Metaphors in Teaching Business and Management Subjects
}

\section{Nuria Camps}

\author{
Perth College, University of Highlands and Islands, UK
}

\begin{abstract}
:
The use of visual metaphors has received growing attention in recent years, but their widespread use is not without certain challenges. The most common critique of visual metaphors in teaching indicates that they can be misleading as the meaning attributed by the recipient can be far apart from the intended one. This can make learning less intuitive and even create confusion. This paper explores the merits and demerits of the use of visual metaphors in business education.
\end{abstract}

Keywords: Visual Metaphors; Business Education; Sense-Making

Received: 15 June 2020

ISSN 2056-757X

Revised: 21 July 2020

Accepted: 28 August 2020

https://doi.org/10.18646/2056.73.20-024 


\section{Introduction}

The use of metaphor aids learning through the storytelling, rich imagery, and relatable fictional settings associated with it. Through linguistic metaphors, business students can envision the complexities of management theory and practice and related challenges faced by organisations. The linguistic metaphors presented by Gareth Morgan in Images of Organization have been having a significant impact upon organisational studies and business education, inspiring thousands of students, practitioners and scholars over the decades since the book was published in 1986. This long-lasting appeal of the metaphors introduced lies in their simplicity and potential to evoke mental images which communicate complex theoretical concepts to a novice audience and then guide further independent exploration of theory leading to a deeper understanding. Business educators have since relied on the introduced metaphors to creating mental imagery of course material.

Combining visualisation and metaphor would help to understand the construction of meaning and sense-making. Visual metaphors can enrich teaching and learning, in formal and informal educational settings. Given technological advances and improved connectivity, it is convenient to illustrate with and share visual metaphors. This potential for material visualisation can prompt new pedagogies that move away from the notion that business education is dry and even dull.

This article seeks to explore the use of visual metaphors in business and management education. Existing research suggests that visual metaphors can help students to focus more on the subject matter, facilitate greater understanding of complex issues, and promote deeper learning. In order to demonstrate this potential of metaphorical thinking the conceptual and perceptual metaphors are reviewed and then the ways visual metaphors enhance cognitive processes are examined.

\section{Metaphors and sense-making}

McQuarrie and Mick (1999: 39) described metaphor as "one form of artful deviation from reality with their literally false but nonetheless illuminating equation of two different things". Metaphor differs from analogy and comparison where both subjects must be simultaneously considered. On the contrary, the audience for metaphor must find similarities between the two subjects or objects, even though they are of different kinds (McQuarrie and Mick, 1999; McQuarrie and Phillips, 2005). Metaphor represents "a type of indirect claim because they make claims in a figurative way rather than in a literal way" (McQuarrie and Phillips, 2005: 8).

Metaphors can be visually illustrated or explained in textual or auditory modes. Visual metaphors combine abstract conceptualisation, sense-making, and visualisation. They offer a reference point to help in making sense of complex subject matter with the aid of visual images. Visual metaphors can be static or utilise kinaesthetic imagery. While some scholars put the emphasis on the creator and viewer when defining visual metaphors, others employ a set of strict rules in defining visual metaphors (Serig, 2006). Dent and Rosenberg (1990: 984), for example, apply a restrictive definition for pictorial metaphor: first, no words are used; second, two dissimilar subject-matters must bear actual resemblance; third, the resemblance needs to be explicit. Such a restrictive definition of pictorial metaphor not only rules out textual messages that are

International Journal of Management and Applied Research, 2020, Vol. 7, No. 3 
sometimes are embedded in the imagery portraying the metaphor (Jeong, 2008) but also overlooks the role of creator and viewer in its interpretation. Serig (2006) suggests on the contrary that the creation and use of visual metaphors involve inferential effort on the part of creator and viewer who attempt to share a somewhat similar imaginative interpretation guided by personal experience that resonates with them.

Unlike verbal metaphors, which aim to link two concepts or subjects analogously, visual metaphors tend to be more indirect and inferential, and at the same time allow for multiple possible interpretations (Jeong, 2008). In practice, visual metaphors are commonly found in advertisements: for example, ExxonMobil's marketing campaign "put a tiger in your tank" (see Figure 1) suggests that its fuel has qualities similar to a tiger in terms of speed and power. A more challenging example would be a picture of a measuring cup filled with blue sky as depicted by Tide. The recipients, or audience of such images, have to infer that the use of Tide detergent makes clothes as white as clouds or as clear as the sky or as fresh as breeze (see McQuarrie, and Phillips, 2005). The question remains whether the recipients or audience are persuaded by such an implicit communication strategy. Recipients of visual metaphors are often encouraged to develop multilayered meanings that are not explicitly enclosed in a verbal or textual form. They are presumably willing to exert as little effort as possible to process the underlying message (van Mulken et al., 2014), and so the complex implicit communication strategy might not work.

Figure 1: Put a Tiger in Your Tank

\section{PUTA AIGER IN YOUR TANK! PUT A TIGER IN YOUR TANK!}
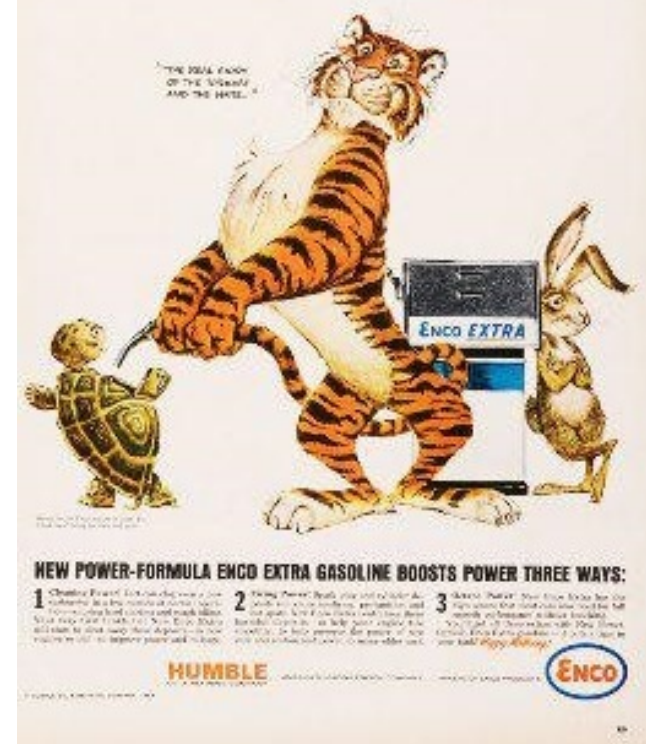

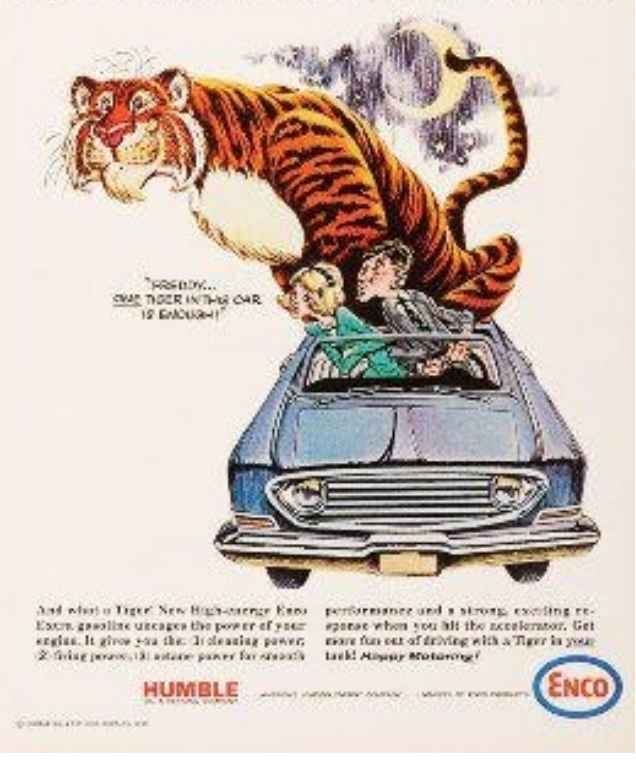

Source: ExxonMobil (2015)

McQuarrie and Phillips (2005) raised concern about the misleading potential of visual metaphors commonly used in advertisements. Comprehension is a necessary prerequisite for visual metaphors to be effective (van Mulken et al., 2014). The audience may fail to grasp a visually complex metaphor or metaphor that is 
cognitively demanding. Given the absence of methodology in evaluating metaphors, McCourt (1997) challenged the applicability of metaphors in practice and questioned whether metaphors stimulated creative actions or organisational changes. Similarly, Pigliucci and Boudry (2011) claimed that metaphorical thinking is sometimes misleading, while Oswick et al. (2002) raised concerns as to whether metaphorical thinking facilitates intuitive reflection for practitioners and students. The novelty of metaphors might induce errors in perception; however, when the meaning is delivered and understood, metaphorical messages can be very persuasive (Jeong, 2008).

\section{Conceptual Metaphors}

Conceptual metaphor theory sees metaphors as a fundamental part of human cognition (Gibbs, 2011), because metaphors inform the way we think and act (Lakoff and Johnson, 1980). Conceptual metaphor theory is commonly used as an explanatory theory of metaphors (Wynder, 2018). According to Lakoff and Johnson (1980: 5), metaphor is primarily conceptual and it is about "understanding and experiencing one kind of thing in terms of another". Therefore, the use of metaphors can be seen as triggering a cognitive process rather than being treated as a linguistic term. Conceptual metaphor theory suggests any form of communication -- verbal or visual -

- can be seen as an instance of metaphor, if it delivers a figurative meaning (Refaie, 2003). However, defining a metaphor in cognitive terms is also not without challenges as it raises a series of difficult questions.

In his seminal work on the conceptual metaphor theory, Lakoff (1993) argued that human bodily experience is widely similar and thus basic level metaphors can be easily shared and understood by people in different places, contexts and times. This view is criticised by Gibbs (2011), who does not accept the view that bodily experience is "universal", instead he asserts that the comprehension of metaphor is subject to context-dependent contingencies, current circumstances, historical narratives and cultural significance. Comprehension of metaphoric similarity also varies according to age, with adults being able to understand visual metaphors quicker based on resemblances between different kinds of objects (Dent and Rosenberg, 1990). A metaphor used in communication is "retrieved" from long-term memory and injected with a new meaning to help interpret a particular metaphorical utterance (Gibbs, 2011). This view explains why comic strips or political cartoons are readily understood by all except preschool children or individuals who are unfamiliar with the context (Refaie, 2003).

Studies that examine cross-cultural differences in interpreting metaphors are well documented (Deignan, 2003 and Littlemore, 2003). Different cultures have different perceptions and attitudes to a particular metaphor, where certain cultural values and norms are more salient in one culture than another. Deignan (2003) and Littlemore (2003) argued that metaphors are culturally-loaded expressions, where the comprehension of a given metaphor is determined by shared cultural knowledge and clues corresponding to cultural expectations. In studying the effect of cultural background on metaphor interpretation, Littlemore (2003) reported that the understanding of metaphors varies according to cultural background: for example, Bangladeshi students do not see "freeing external trade" as a good thing due to the fact that the idea of liberalisation and free trade do not feature prominently in their

International Journal of Management and Applied Research, 2020, Vol. 7, No. 3 
socio-economic context. Deignan (2003) illustrated how bull-fighting is readily found in Spanish metaphors but is not at all prominent in English ones.

The assumption of a universal bodily experience raises a number of questions: should the use of conceptual metaphors disregard socio-political contexts that are deeply rooted in different countries? How to translate a culturally bound metaphor (e.g. bullfighting) into a universally understood conceptual metaphor, if needed?

\section{Perceptual Metaphors}

The concept of the perceptual metaphor offers another viewpoint on metaphors as devices that can provoke new interpretations of familiar objects (van Weelden et al., 2011). Rather than being realigned with shared beliefs and norms, perceptual metaphors can trigger meanings through new representations of the object based on its properties such as shape, function or colour. For example, a similarity in shape might facilitate meaningful associations between two objects having the same shape. Circular objects then share similar features, such as the ability to roll, leading to a logical assumption that all circular objects are roll-able, irrespective of size or weight. Exploiting perceptual similarities to convey the metaphorical meaning is the essence of perceptual metaphor (Refaie, 2015; Ervas, 2020; van Weelden et al., 2011).

Perceptual metaphors provide ground for Perceptual Simulation Theory which is about "simulating in our minds what it would be like to actually perceive the things that are being described" (Refaie, 2015, p. 63). Mental images are different from photos or illustrations. Mental images combine person's imagination with sensory information which once stored can be recalled from the memory and re-interpreted. Based on an assumption that words can trigger recall of mental images (Ervas, 2020), Perceptual Simulation Theory suggests that metaphors using perceptual resemblance are no less influential than conceptual metaphors (Refaie, 2015). The "imagistic" and conceptual routes to communicate meaning are not mutually exclusive, but the perceptual pathway puts more emphasis on recall and re-interpretation of mental images in understanding metaphors than on deliberate thought process.

\section{The use of visual metaphors in education}

\subsection{The Why Factor: Merits}

Visual metaphors can be used as a basis for generating further managerial insights and facilitate critical thinking, helping non-English speaking students to overcome cultural and linguistic challenges (Wynder, 2018). In a study of metaphorical images of culture, Ryan (1996) noted that visual metaphors provide the elusiveness of cultural concepts while developing sociolinguistic goals. In an increasingly visualised digital environment, visual metaphors can generate new metaphorical insights that can be further developed by imagery and analogy. Taylor et al. (2018) present an illustration of how visual metaphor and digital storytelling can be intertwined to increase student engagement in accounting classes. Similarly, Wynder (2018) uses multimedia digital learning objects as means to reduce the cognitive load for non-English speaking students, which is proven to be effective. Osgerby et al. (2018) demonstrate how visual metaphor can be used to aid personal development planning for students in a non-written form but in a rich and expressive manner, allowing them to reflect more holistically about their personal development. The argument is that not all students

International Journal of Management and Applied Research, 2020, Vol. 7, No. 3 
can immediately comprehend theoretical concepts and the use of visual tools provides an alternative cognitive approach that allows students to process different pieces of information using visual stimuli.

As the saying goes: "a picture is worth a thousand words", an illustration or an image is able to convey a complex message in a more immediate and effective manner than a mere verbal description (Refaie, 2003). A typical visual metaphor is based on reinterpretation of pre-existing familiar conceptualisations of activities and/or objects. Visual metaphor interpretation involves questioning existing beliefs and seeking information to "fill in the gap" in order to makes sense of the conceptual disruption (Ervas, 2020). Interpreting visual metaphor is thus a rewarding experience and the feeling of reward has been described as "solving the riddle" (Refaie, 2003, van Mulken et al., 2014). Van Mulken et al. (2014) reasoned that, in understanding a visual metaphor, the greater cognitive effort leads to higher satisfaction; however, the viewer might withdraw from metaphor interpretation if the metaphor is visually complex or cognitively challenging. In short, not everyone is interested and committed to understanding a visually evocative metaphor.

\subsection{The Why Factor: Demerits}

Pigliucci and Boudry (2011) highlighted the need to foster a cautious attitude towards metaphorical thinking because outdated metaphors could lead to misunderstanding due to the inherent limitation of metaphor: the partiality of insight (Morgan, 1986). A metaphor provides a partial view, instead of showing the whole picture. The poem "The blind men and the elephant" written by John Godfrey Saxe best illustrates the partially of insight. The students are left to interpret metaphors on their own, and an inappropriate metaphor could lead to misinterpretation or misunderstanding. Ervas (2020) argued that visual metaphors are vague, and their irrelevant visual properties might impede reasoning as viewers might pay too much attention to visual details that are irrelevant to the intended metaphorical meaning.

Bruguière et al. (2018) demonstrated how generalised concept of metamorphosis could potentially hinder the accurate comprehension of biological transformations. Equally, Pigliucci and Boudry (2011) illustrated that the limitations of using blueprint metaphors in teaching biology is that the metaphor can become outdated and inadequate with time. The findings of Bruguière et al. (2018) and Pigliucci and Boudry (2011) are consistent with Oswick et al. (2002) who argued that metaphor tends to promote analytical closure as a way of understanding a complex subject matter rather than facilitate knowledge generation.

As the number of academic studies related to metaphorical thinking continue to grow, it is necessary to review the limitations of using metaphors in education and identify areas where further improvement is needed. McCourt (1997) noted that the absence of agreed evaluation criteria leads to a risk of cognitive bias and thus he calls for a welldefined methodology to evaluate goodness of fit for metaphors. Pigliucci and Boudry (2011) suggested that metaphorical thinking should be promoted in a cautious manner and that one way of doing it is to contrast different metaphors with the goal of highlighting the deficiencies of metaphorical argument. Similarly, Bruguière et al. (2018) called for a more cautious attitude towards an integrated pedagogical approach that combines fiction and science literature. Littlemore (2003) suggested that lecturers should replace "chalk and talk" lecturing with a more opened, debate-like style so that

International Journal of Management and Applied Research, 2020, Vol. 7, No. 3 
students could raise concerns highlighting any confusion, explore metaphorical meaning collaboratively, and identify cultural differences. Interestingly, Oswick et al. (2002) suggested the use of irony and paradox as alternatives to metaphors in developing more in-depth analytical thinking.

\section{Conclusion}

This paper offers an overview of the current use of linguistic and visual metaphors in business education reflecting on the need for a more visualised, engaging approach to teaching and learning grounded in a focused use of visual representation of academic concepts. The use of visual metaphors in business education is on the rise, mainly because of the potential of visual metaphors to combine the essence of perceptual and conceptual metaphors, while aiming to visualise metaphors in a vivid, condensed fashion and forcing learners, as viewers, to rethink their existing beliefs and comprehend the intended meaning behind metaphors.

The benefits of using visual metaphors in business education are already welldocumented. Empirical studies concluded that visual metaphors helped to relate course materials to real life settings and assisted in grasping complex abstract processes (Taylor et al., 2018; Osgerby et al., 2018; Wynder, 2018). Wynder (2018) showed that carefully chosen visual metaphors could help avoid cognitive overload for students when learning new topics. Osgerby et al. (2018) reported that the use of visual metaphors allows students to express their emotions and thoughts more freely compared to written work. Taylor et al. (2018) found that the combined use of digital storytelling and visual metaphors resulted in a higher level of student engagement compared to a control cohort.

Metaphors however have the capacity to be misused and/or misunderstood. The ability to grasp metaphorical meaning varies across cultures, mainly due to different cultural values and norms. The comprehension of metaphors relies on shared experience of observable natural objects and past events. Cultural differences may therefore hinder interpretation of metaphors thereby diminishing the power of metaphorical discovery and persuasiveness.

Establishing the goodness of fit for metaphors, particularly the visual ones, requires a consensus among educators, which is currently lacking (McCourt, 1997). Future research can explore the ways of developing and evaluating visual metaphors in a less restrictive but creative manner and that would enable a more widespread use of visual metaphors.

\section{References}

1. Bruguière, C., Perru, O. and Charles, F. (2018), "The Concept of Metamorphosis and its Metaphors", Science \& Education, Vol. 27, No. 1-2, pp. 113-132. https://doi.org/10.1007/s11191-018-9959-x

2. Deignan, A. (2003), "Metaphorical Expressions and Culture: An Indirect Link", Metaphor and Symbol, Vol. 18, No. 4, pp. 255-271. https://doi.org/10.1207/S15327868MS1804_3

International Journal of Management and Applied Research, 2020, Vol. 7, No. 3 
3. Dent, C. H. and Rosenberg, R. (1990), "Visual and verbal metaphors: Developmental interactions", Child Development, Vol. 61, No. 4, pp. 983-994. https://doi.org/10.2307/1130870

4. Ervas, F. (2020), "Metaphor, ignorance and the sentiment of (ir)rationality", Synthese, https://doi.org/10.1007/s11229-019-02489-y

5. ExxonMobil (2015), Put A Tiger in Your Trunk, [Online] Available from: https://twitter.com/exxonmobil/status/553663807772712960 [accessed on 28 June 2020].

6. Gibbs, R. W. (2011), "Evaluating Conceptual Metaphor Theory", Discourse Processes, Vol. 48, No.8, pp. 529-562. https://doi.org/10.1080/0163853X.2011.606103

7. Jeong, S. H. (2008), "Visual Metaphor in Advertising: Is the Persuasive Effect Attributable to Visual Argumentation or Metaphorical Rhetoric?", Journal of Marketing Communications, Vol. 14, No. 1, pp. 59-73. https://doi.org/10.1080/14697010701717488

8. Lakoff, G. (1993), "The contemporary theory of metaphor", In Ortony, A. (Ed.), Metaphor and Thought, New York: Cambridge University Press. pp. 202-251. https://doi.org/10.1017/CBO9781139173865.013

9. Lakoff, G. and Johnson, M. (1980), Metaphors we live by, Chicago, IL: University of Chicago Press.

10. Littlemore, J. (2003), "The Effect of Cultural Background on Metaphor Interpretation", Metaphor and Symbol, Vol. 18, No. 4, pp. 273-288. https://doi.org/10.1207/S15327868MS1804_4

11. Morgan, G. (1986), Images of Organization, London: Sage.

12. McQuarrie, E. F. and Mick, D. G. (1999), "Visual rhetoric in advertising: text interpretive, experimental, and reader-response analyses", Journal of Consumer Research, Vol. 26, No. 1, pp. 37-54. https://doi.org/10.1086/209549

13. McQuarrie, E. F. and Phillips, B. J. (2005), "Indirect Persuasion in Advertising: How Consumers Process Metaphors Presented in Pictures and Words", Journal of Advertising, Vol. 34, No. 2, pp. 7-20. https://doi.org/10.1080/00913367.2005.10639188

14. McCourt, W. (1997), "Discussion note: Using metaphors to understand and to change organizations: A critique of Gareth Morgan's approach”, Organization Studies, Vol. 18, No. 3, pp. 511-522.

https://doi.org/10.1177\%2F017084069701800307

International Journal of Management and Applied Research, 2020, Vol. 7, No. 3 
15. Osgerby, J.; Marriott, P. and Gee, M. (2018), "Accounting students perceptions of using visual metaphor as part of personal development planning: an exploratory case study", Accounting Education, Vol. 27, No. 6, pp. 570-589. https://doi.org/10.1080/09639284.2018.1523735

16. Oswick C, Keenoy T and Grant D (2002), "Metaphor and analogical reasoning in organization theory: Beyond orthodoxy", Academy of Management Review, Vol. 27, No. 2, pp. 294-303. https://doi.org/10.5465/amr.2002.6588045

17. Pigliucci, M., Boudry, M. (2011), "Why Machine-Information Metaphors are Bad for Science and Science Education", Science \& Education, Vol. 20, No. 5-6, pp. 453-471. https://doi.org/10.1007/s11191-010-9267-6

18. Refaie, E. E. (2003), "Understanding visual metaphor: the example of newspaper cartoons", Visual Communication, Vol. 2, No. 1, pp. 75-95. https://doi.org/10.1177/1470357203002001755

19. Refaie, E. E. (2015), "Reconsidering Image Metaphor in the Light of Perceptual Simulation Theory", Metaphor and Symbol, Vol. 30, No. 1, pp. 6376. https://doi.org/10.1080/10926488.2014.948799

20. Ryan, P. M. (1996), "Sociolinguistic Goals for Foreign Language Teaching and Teachers' Metaphorical Images of Culture", Foreign Language Annals, Vol. 29, No. 4, pp. 571-586. https://doi.org/10.1111/j.19449720.1996.tb01268.x

21. Serig, D. (2006), "A Conceptual Structure of Visual Metaphor", Studies in Art Education: A Journal of Issues and Research, Vol. 47, No. 3, pp. 229-247. https://doi.org/10.1080/00393541.2006.11650084

22. Taylor, M.; Marrone, M.; Tayar, M. and Mueller, B. (2018), "Digital storytelling and visual metaphor in lectures: a study of student engagement", Accounting Education, Vol. 27, No. 6, pp. 552-569. https://doi.org/10.1080/09639284.2017.1361848

23. Wynder, M. (2018), "Visualising accounting concepts: insights from Cognitive Load Theory for English as a Second Language students", Accounting Education, Vol. 27, No. 6, pp. 590-612. https://doi.org/10.1080/09639284.2017.1361847

24. van Mulken, M.; van Hooft, A. and Nederstigt, U. (2014), "Finding the Tipping Point: Visual Metaphor and Conceptual Complexity in Advertising, Journal of Advertising, Vol. 43, No. 4, pp. 333-343. https://doi.org/10.1080/00913367.2014.920283

International Journal of Management and Applied Research, 2020, Vol. 7, No. 3 